\title{
The Framework of a Mathematical Model of the Autonomic Nervous System and Physiological Systems: Using the Neuroregulation of Blood Glucose as an Example
}

\author{
Graham Wilfred Ewing* \\ Montague Healthcare, Mulberry House, 6 Vine Farm Close, Cotgrave, Nottingham, NG12 3TU, England
}

\begin{abstract}
Despite the immense advances of medical research there remains a fundamental theoretical deficit regarding how the body is able to maintain its physiological stability. In other words, what is the mechanism which regulates homeostasis and allostasis and/or what is the relationship between genotype and the influence of the environment (phenotype)?

Despite the immense amount of publicity given to the huge increases in the occurrence of the most common lifestyle related ailments (e.g. diabetes, obesity, cardiovascular disease, cancers, Alzheimer's disease, etc) which have occurred in recent years; most people in the world still have relatively normal levels of body weight and remain free from medical problems during their lifetimes, at least until their advancing years when their body is increasingly less able to maintain its normal regulated function.

This article considers whether it is now possible to understand the nature, structure and function of this regulatory mechanism in far more detail than has hitherto been possible. This neuroregulatory mechanism involves the influence of light upon brain function and hence upon the autonomic nervous system and physiological systems. There is a particular emphasis in this article upon the regulation of Blood Glucose and how Acidity plays a significant role in diabetes etiology. Finally, the article introduces a Mathematical Model of the Autonomic Nervous System and/or the Physiological Systems (developed by Dr IG Grakov) which has been incorporated into a commercialised technology which is based upon the concepts outlined.
\end{abstract}

Keywords: Mathematical model, autonomic nervous system, physiological systems, genotype, phenotype

\section{Introduction}

Our sense perception enables us to eat the correct amounts of food and, under normal circumstances, we cease eating when we have eaten sufficient food, and we drink sufficient to satisfy the body's need for liquid. We breathe at the normal expected rate, our heart pumps at the expected rate and maintain the normal level of blood pressure, our body maintains the normal levels of acidity and temperature, we sleep for 7-8 hours per night, etc. This suggests that the body is being regulated by a biological control mechanism of enormous sophistication and complexity, which has an enormous processing capacity; however as we age, and particularly as we age beyond 50 years, the mechanism which maintains our function become increasingly less able to sustain the levels of oxygen, blood glucose, blood cell content and a myriad of other biological components which the brain requires to function [1]. The i nnate g enetic $\mathrm{c}$ apacity of key o rgans d eclines a nd $\mathrm{r}$ esults in shortages of proteins, hormones, etc. This $\mathrm{h}$ as a k nock-on e ffect affecting one biological sequence after another.

The cumulative effect of our lifetime of experiences, due to environmental and biological factors, influences the function and/ or stability of the autonomic nervous system and ultimately the function of our DNA and genes [2]. The level of genetic expression of the proteins (genotype) which we require to sustain our function declines and the rate at which these expressed proteins subsequently react (phenotype) also declines i.e. the ability of the body to cope with extreme events declines.

There are two fundamentally significant biological issues at play: (i) the genetic ability to express proteins (ii) the body's physiological demand i.e. the phenotype or influence of the environment. In the case of diabetes, in particular type 2 diabetes, this is the regulation of Blood Glucose. The greater the level of hyperglycaemia the greater is the associated demand for insulin. The development of a medical condition occurs when the environmental demand exceeds the body's innate capacity [3] i.e. the prevailing supply and/or level of insulin is insufficient to metabolise the excess of blood glucose. By contrast, the lower the level of hypoglycaemia, which occurs in type 1 diabetes, the lower is the demand/need for insulin. If there is insufficient blood glucose the excess of highly reactive insulin will seek an alternative substrate and ultimately results in damage to the peripheral blood vessels e.g. in particular to the brain, eyes, legs and feet.

The evidence suggests that this regulatory process is performed by the brain via the process of neuroregulation [4-6]. This is a best-fit process which takes into account the prevailing state of development or physiological damage to a part of the brain, degeneration or damage to an organ (or limb), and the prevailing inter-cellular environment i.e. the feedback of biochemical signals from the viscera.

*Corresponding author: Graham Wilfred Ewing, Montague Healthcare Mulberry House, 6 Vine Farm Close, Cotgrave, Nottingham, NG12 3TU, UK, Tel: 0115-9890304/9899618; Fax: 0115-9899826; E-mail: graham.ewing@montague-diagnostics.co.uk

Received November 04, 2014; Accepted December 26, 2014; Published January 21, 2015

Citation: Ewing GW (2015) The Framework of a Mathematical Model of the Autonomic Nervous System and Physiological Systems: Using the Neuroregulation of Blood Glucose as an Example. J Comput Sci Syst Biol 8: 059-073. doi:10.4172 jcsb.1000172

Copyright: @ 2015 Ewing GW. This is an open-access article distributed under the terms of the Creative Commons Attribution License, which permits unrestricted use, distribution, and reproduction in any medium, provided the original author and source are credited. 
The regulation of Blood Glucose, Blood Pressure, Acidity, Sleep and other essential biological and biophysical factors exhibit the characteristics of neurally regulated Physiological Systems. They involve many different causal factors, are polygenomic and multipathological, and yet are regulated within homeostatic limits e.g. hyperglycaemia and hypoglycaemia, hypertension and hypotension, acidosis and alkalosis, and hypersomnia and hyposomnia (insomnia).

Although it may seem an obvious conclusion, at least to the layman, the existence of neurally regulated physiological systems has never been proven although the idea of a complex network of neural networks involving cognitive influence over functional systems is not new [7]. Nevertheless medical reference journals continue to cite the contemporary definition of physiological systems which appears to be at variance with accepted medical findings $[8,9]$. This process of neuroregulation may be responsible for all aspects of our function and behaviour [10] e.g. sensing nutrients, activating neuronal functions, and regulating homeostasis [11]; except in chronic cases where organ systems are unable to respond to the neural instructions to return an organ to homeostasis. This phenomena has been extensively researched in Russia and recognised as a 'pathological functional system' [12,13] in which organs appear to function in stable systems i.e. at variance from normal physiological system(s).

The body simultaneously receives a complex array of sensory input and biological input. It is designed to be mentally and physically active. The brain regulates the autonomic nervous system and the physiological systems [14]. It does so continuously throughout the 24 hour cycle, in particular when we are awake, when we are participating in extreme events [5], and when we are asleep. This leads us to consider the relationship between brain function, the neural (EEG) frequencies, and cellular and molecular biology $[8,14,15]$.

The contemporary understanding is that these functional systems are neurally regulated, that control is exerted by the autonomic nervous system and the endocrine system, that the brain contains programs which regulate the coordinated function of the body's tissues and organs [16], and that the coordinated function of different regions of the brain is an essential element of emotions and behaviour.

Changes of brain function have biological correlates which are manifest at the molecular level as changes to cellular and molecular biology, in particular to genotype and phenotype. Moreover insulin is produced in the brain in addition to the pancreas [17]. Accordingly what is the mechanism which simultaneously maintains the levels of blood glucose in the brain and the body? Is it autonomous or is it neurally regulated? The evidence suggests that the physiological processes function as part of a highly regulated network of physiological networks [18].

The regulation of blood glucose exhibits the characteristics of a remotely regulated system [19]. That it is a neurally regulated system explains the release of insulin in cycles of typically 6-15 minutes duration [20]. If someone is healthy the cycle is typically 6 minutes whereas if someone is diabetic the cycle can be up to 15 minutes. By contrast, changes of biological levels e.g. of insulin and blood glucose, influence brain function and behaviour. We seek out food when our blood glucose levels start to decline and we may ultimately become agitated if we get hungry. There is a dynamic relationship between the function of the brain and the visceral organs (Figure 1).

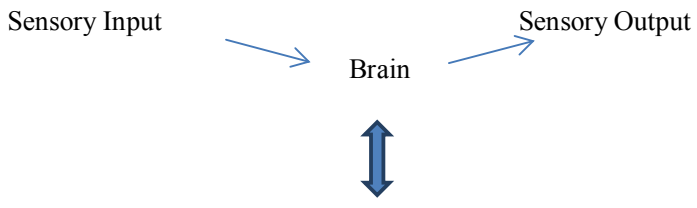

Visceral Organs

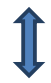

Figure 1: Brain vs. Viscera

\section{The Relationship between Sensory Input and Biological Input}

The brain and the body respond to sensory input. Deprivation of sensory input can inhibit neural development and/or lead to the shrinkage of elements in the brain whilst nurturing e.g. during childhood or during recovery from injury, enhances neural development $[21,22]$ and also the development of autonomic stability. In addition, the devotion to specific activities during childhood or adulthood, which we know more typically as education or training, leads to the enhanced growth of specific components and also the growth of specific organs in the brain or body, the growth and/or function of specific muscle groups, etc. By contrast, an excess of sensory input can overload the innate perceived capacity of the brain. Whatever we do, how we do it, and whatever we consume (including viruses, vaccines, drugs, and our food/nutrition) influences the body's stability and function to some extent however stress is a person-specific concept. We can be trained to accommodate stress e.g. (i) a child raised in a loving caring environment from birth is less susceptible to stress or (ii) a pilot can be trained to cope with unexpected problems which may occur whilst flying a military or passenger aircraft. Stress is a learned constraint. We remember most vividly the most stressful events which have caused pain or injury i.e. memory is a multi-level component of how the brain regulates the body's function. We can develop coping strategies which enable us to more easily deal with stressful experiences.

The nature and extent of the stressor influences the body's pathological correlates e.g.

(i) the stress may have low intensity but a high level of frequency or it may have a high level of intensity but is infrequent;

(ii) the psychological and/or physiological nature of the stress i.e. if it created change of short-term or long-term physiological significance (the acute or chronic condition);

(iii) the age, gender, and health profile of the patient (including weight) i.e. as we age our ability to be influenced by stress-related events increases.

(iv) the stress may have different EEG correlates i.e. influencing the body's function at different levels [8].

(v) the stress may have multiple pathological correlates which cannot be precisely characterised by a single biological determinant $[4,23]$.

(vi) changes to genetic expression could affect more than one physiological system [24] e.g. the genes which influence the quality and quantity of sleep could also influence the regulation of blood glucose; 
or proteins which are involved in the immune function also influence cardiovascular health [25].

This may explain the apparent lack of effectiveness of many drugs. With the possible exception of antibiotics, drugs are about $50 \%$ effective [26]. Furthermore they depend upon the autonomic nervous system for their effect and this changes according to age, weight and gender i.e. the majority of patients treated by the healthcare system are overweight or elderly. Drugs based on phenotype are usually unnatural products which are designed to interfere with the pathological process without causing significant disruption to the autonomic nervous system. If used at too low a level they are ineffective whilst if used at too high a level they are often toxic. Accordingly, there must be a reason which can explain the missing $50 \%$.

Apart from inherited genetic defects, or of damage or deformation to a physiological component, the fundamental cause of most common medical conditions is psychological or biological i.e. stress creates systemic dysfunction whilst a drug suppresses the biological consequences of the condition and may enable the brain to recover a degree of autonomic stability. Alternatively the nature of the stress may be of sufficient severity or systemic complexity that drugs are unable to compensate for the over-riding effect of the stress upon the autonomic nervous system. In order to understand the issue in greater detail we must consider (i) the fundamental relationship between genotype (protein expression) and the wider influence of environmental factors i.e. non-genetic or phenotype [27] and, (ii) the mechanisms which the brain uses to regulate the body's function [28] and vice versa (Figure 1).

\section{Genotype}

Under normal circumstances (i) our genes express sufficient proteins to sustain our function (genotype) and (ii) the intercellular environment in which these expressed proteins react with their reactive substrate e.g. the prevailing level of intercellular acidity, is sufficient to sustain the reactivity of these proteins (phenotype) however changes of genetic and/or epigenetic structure (chemical and morphological), must also influence biological outcomes.

The development of genetic screening enables the medical researcher to identify which genes are involved in the complex process of protein expression. This process is complicated for several reasons:

(i) genetic screening techniques may differ and give different results, and/or the results may not be reproducible;

(ii) it is rare for a single gene to express a particular protein-often a gene will be involved in the expression of more than one protein;

(iii) the spectrum of genes which are involved in the process of expressing a particular protein may differ e.g. between racial subtypes $[29,30]$;

(iv) the expression of a gene must adhere to the laws of chemistry and/or physics i.e. the reaction conditions, in particular acidity, influences the prevailing levels of essential minerals (e.g. chromium, magnesium and zinc) and hence the function of transcriptase enzymes which require magnesium as a cofactor;

(v) epigenetic effects (e.g. methylation, phosphorylation, the adsorption of transitional metals, etc) also influence gene conformation [31] and hence must influence the rate of protein expression; and (vi) is the genetic change the cause or the consequence of the medical condition $[32,33]$ ?

Changes to gene conformation influence our function and predisposition to stress e.g. the level of the immune response determines our predisposition to a virus or vaccine i.e. it influences the genetic expression of proteins. Genetic changes can be inherited, acquired or due to environmental factors (viruses, vaccines, genetically modified organisms, etc) however the issue cannot solely be explained by considering just the biochemistry of the DNA and genes. Of greater significance is that such changes to genetic chemistry are accompanied by changes to gene conformation, which influences the structural and spatial relationship between a number of different and/or adjacent genes. This influences their synergistic function and subsequently the genetic expression of a particular protein(s). It explains why the genetic spectrum of different racial groups may differ e.g. in the expression of the insulin precursor.

The onset of type 1 diabetes is associated with changes of gene conformation as a result of interaction with viruses [34-42] and viruslike particles [43-45], the subsequent development of genetic and epigenetic variations [31] and/or of altered proteins which influence the immune response [46] and the subsequent production of antibodies i.e. the level and spectrum of antibodies may be the consequence of changes to gene morphology. Nevertheless the precise nature of this mechanism i.e. of type 1 diabetes, remains beyond the current level of understanding.

The issue is further complicated by evidence which suggests that the pancreas does not completely lose the ability to express insulin [47] This appears to contradict the contemporary explanation that type 1 diabetes is an auto-immune condition which causes destruction of beta cells in the Islets of Langerhans by T-cells. If so, this should result in the complete elimination of the beta cells to express insulin but this appears not to be the case. The evidence appears to suggest that changes to the immune system i.e. the antibodies produced, may be the consequence of the condition rather than its cause. This appears to indicate that the production of antibodies is in response to a viral infection rather than being 'an auto-immune condition which causes destruction of beta cells in the Islets of Langerhans by T-cells'. The prevailing theory is not supported by recent research [48].

Low levels of magnesium are often found in the type 1 diabetic [49]. This may be highly significant. It may be indicative of a dietary deficiency of magnesium but it could also be the consequence of a higher levels of intercellular acidity e.g. due to lack of exercise [50] and/or a magnesium deficient diet; which would influence the genetic expression of prepro-insulin, the coiled or uncoiled nature of insulin, the inability to metabolise blood glucose in the musculature, the inability of the pancreas to store insulin, and the ability of the expressed protein insulin to react with its receptor. It would also contribute to lowered immune function [51-53] and greater susceptibility to infection. This appears to be confirmed by the positive effect of magnesium supplementation [54] and by noting the relationship between magnesium levels of glycated haemoglobin [55] in the type 1 diabetic. The regulation of 'the levels of blood glucose' is influenced by acidity - both blood glucose and acidity are neurally regulated physiological systems [19].

As stated earlier, the issue of significance is not just what proteins are being expressed but instead by how much are these proteins being expressed [56]. For example genetic factors can create a physiological problem without the phenotype e.g. the shortage of an enzyme in Gaucher's disease [57] and Fabry's disease [58]; however the nature 
of the condition, in particular when the condition worsens, inevitably leads to stressful experiences i.e. the influence of environmental factors (phenotype), becomes increasingly significant. We experience stress as a complex set of biological correlates which affect the body's subsequent functional capacity.

\section{Phenotype}

Stress in its many various manifestations is a fundamentally acidic process [59]. It increases the prevailing levels of acidity in the brain and in the body $[59,60]$. Exposure to stress suppresses the natural balance of the autonomic nervous system. Extreme levels of stress influences the expression of insulin [61], the function of the brain, the endocrine glands [62] and subsequently the expression of endocrine hormones [63]. For example stress may lead to (i) the onset of dysfunction of the lungs and bronchii, the progressive inability to eliminate $\mathrm{CO}_{2}$ [64], and reduced expression of glucocorticoids [65], the bronchii are constricted and/or able to perform the task of oxygen exchange which leads to the occurrence of the bronchiectactic spasms that are typical of the asthmatic type condition; (ii) gastric reflux in which digestive acidity 'refluxes' in the oesophagus [66]' (iii) the release of digestive acidity into the small intestines which leads to the irritation of the intestinal lining and to the rapid elimination of digestive contents i.e. diarrhoea [67]; (iv) the expression of different thyroid hormones [68]; etc.

Changes to the nature and/or levels of the proteins which are expressed alter the cellular orientation of proteins and their reactive substrates. All proteins, peptides, amino-acids, and fats/fatty acids are polar therefore changes of acidity influence their spatial orientation in the cell and/or their physical structure/morphology. The level of essential minerals changes if cellular $\mathrm{pH}$ is altered [69]. The reaction of acidity with essential minerals creates less soluble or insoluble salts therefore an increase in intra-cellular and/or intercellular acidity must inevitably be accompanied by a steady decrease in the level and/or bioavailability of essential minerals e.g. magnesium, calcium, chromium, selenium, zinc, etc; and by an increase in the levels of transitional minerals e.g. iron, aluminium, mercury, etc. Accordingly, as many enzymes and proteins require magnesium and/or zinc as cofactors [70], it becomes increasingly evident that increases of acidity must inevitably be accompanied by reduced metabolic rate and the subsequent manifestations thereof e.g. to body weight.

The same phenomena is manifest in the long-distance runner i.e. reductions of body fat and excess training leads to an increase in levels of magnesium and zinc but a decline in the levels of iron which results in anaemia [71-73]. If so, this would be manifest in others who have low body weight e.g. in those with anorexia nervosa, and this is found to be so $[74,75]$. Such changes to the prevailing levels of intercellular and intracellular acidity influences the levels of essential minerals, hydration levels in the cell, and also the volume of the cells. This is the classic inflammatory response. Moreover as most transcriptase enzymes require magnesium i.e. as a cofactor, it becomes apparent that increased levels of acidity must also influence genetic expression [76].

The environment which supports oxidative stress and the formation of reactive oxygen species which is damaging to cell structure often includes increased levels of acidity and increased levels of iron and other components. Indeed, the damage caused by oxidative stress and subsequent changes of cell morphology must inevitably influence organ function. It is inconceivable that this would not in some way influence how different cells communicate e.g. (i) between the alpha and beta cells in the pancreas [77], (ii) the ability of the lymphatic mechanism to drain unwanted neurotoxins [78], (iii) the co-ordinated function of heart muscles [79], (iv) communication between endocrines [80], (v) etc.

The definition of Phenotype used in this text is a measure of the rate at which the level of expressed proteins subsequently reacts with its reactive substrate(s). It is a measure of the environmental demand, or influence of the environment, upon the body's functional capacity. This differentiation between genotype and phenotype illustrates why someone with type 2 diabetes could be prescribed insulin which is the accepted treatment for type 1 diabetes i.e. type 1 and type 2 diabetes coexist. This is particularly significant if the correct drug or therapy is to be prescribed and/or if other non-drug therapies are to be recommended.

Furthermore the context in which each medical condition is determined is significant. As we age we steadily lose the ability to express the key proteins which are essential for our function. By the time we have reached 90 years or thereabouts we will have lost $90 \%$ of our capacity to express proteins e.g. pre-pro-insulin/insulin i.e. type 1 diabetes is a condition which everyone experiences at some stages in our lives.

Diabetes and obesity are characterised by an inflammatory response and reduced metabolic rate. This is the consequence of increased levels of acidity, of oxidative stress, increased weight, and hence of increased levels of fatty acids, triglycerides, lipids, glycated proteins, etc [81]. The subsequent increase in body fat leads to increased levels of cellular acidity, cellular hydration and interruptions to intercellular communication. The skin takes on the characteristic texture/flabbiness of someone who is obese which makes it more difficult to regulate body temperature. This influences the rate at which proteins react i.e. reduced metabolic rate.

The influence of the environment (phenotype) does not require a genetic component to influence sleep, stress-related headaches, etc. In general, the pathologies which are related to phenotype result from extreme stress or nutritional deficits.

\section{Genotype and phenotype}

The onset and progression of a medical problem, irrespective of its origins, must also create a stress effect e.g. (i) the lack of physical activity arising from the development of a cardiovascular problem would create increased levels of acidity. It illustrates why exercise is such an effective way of reducing stress [82] i.e. exercise increases blood flow through the lungs and reduces $\mathrm{pCO}_{2}$ in the cells. (ii) The mental stress of being unwell inhibits the body's innate healing response i.e. the autonomic nervous system. It is often referred to as the 'chronic' state. (iii) Someone who develops cancer will become stressed as they and their family worry about the outcomes (Figure 2). This has been extensively researched in neuro-oncology [83] where it has been recognised that the stressful effect of the diagnosis and/or the quality of care provided by nurses or carers is often associated with the level and/ or rate of therapeutic outcomes.

Under normal circumstances i.e. when we are in good health, we express sufficient proteins to cover all eventualities however the influence of stress is benign. As the levels of expressed proteins decline (genotype), and as the rate at which these expressed proteins react (phenotype) slows, the lower becomes the physiological limit(s) in which the body operates. The genotype is therefore a measure of predisposition to a medical condition. It is only when the demand for the expressed protein exceeds the supply of the genetically expressed protein that this results in the onset and/or progression of a medical condition. 


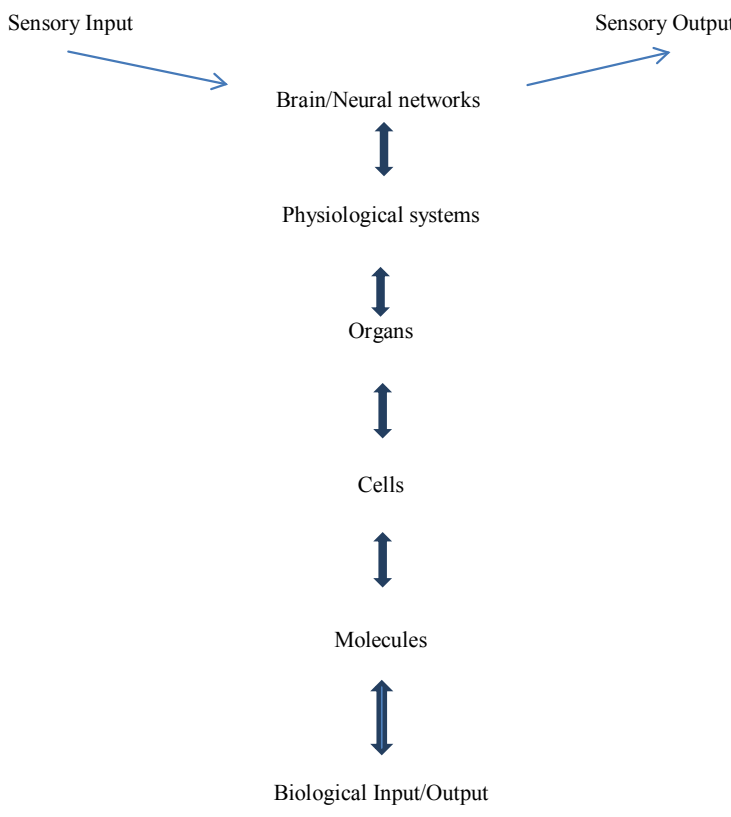

Figure 2: The Structure of the Autonomic Nervous System.

If the rate of reaction of the expressed protein is too low this results in the onset and/or progression of a medical condition. The limits of operation become narrower. It illustrates how a genetic predisposition requires an environmental trigger e.g. in the case of BRCA1 gene in breast cancer or as outlined in this article re diabetes. The problems occur when the influence of stress exceeds the innate genetic capacity and, at that stage, normal biological function can no longer proceed. If the condition is temporary the condition is the 'acute' state whereas if the condition is continuous the condition is the 'chronic' state.

\section{The Criteria for a mathematical model}

A mathematical model of the autonomic nervous system should make the link between sensory input, brain function and cellular \& molecular biology (genotype and phenotype). Indeed if it involves cellular molecular biology, it must also include cellular biology, organ function and the function of the organ systems [14]. Accordingly any technology based upon a mathematical model of the autonomic nervous system would be able to determine the onset and progression of these pathologies at these different levels however, in order to define the nature of each medical condition, it is necessary to consider the levels of a protein or its substrate which are reactive and not just the prevailing level of a component. This is discussed in greater detail in Light and Colour as a Therapeutic Modality section.

Furthermore, by basing such a technology upon a mathematical model of the autonomic nervous system (which derives its data sets from changes of colour perception which arise from the release of biophotons as proteins react) it is possible to evade the side-effects e.g. which affect genetic screening through the inability to precisely define the complex mechanism by which the genes are able to express a particular protein; and takes into account how the prevailing intercellular environment influences the structure of proteins and influences their coiled nature and reactivity, which influences the ability of the reactive protein to react with its receptor. Similarly it evades the side-effects of histopathological tests (including biomarkers) which are often influenced by physical and biological factors [15] including the sampling process, test limits, $\mathrm{pH}$, temperature, light, oxygen, a deficiency of a mineral or substrate, etc.

Strannik Virtual Scanning [84] is able to determine the onset and progression of pathologies at the different levels outlined i.e. molecular, cellular, organ and physiological system. It adheres to Kandel's recognition that there is a fundamental relationship between cognition and cellular \& molecular biology [85] and it meets Noble's specification for a mathematical model [86] of the autonomic nervous system.

\section{Physiological systems}

As outlined, the above changes in organ structure and function influence the function of the organ networks (often referred to as physiological or functional systems). Stress influences the stability of many of the body's physiological systems e.g. sleep $[8,14]$, digestion, excretion, urination, blood glucose [19], blood pressure [87], $\mathrm{pH} /$ acidity [69], blood cell content, respiration, temperature, osmotic pressure, posture (musculo-skeletal structure), and blood volume.

Although this definition of physiological systems differs from the historical definition of physiological systems $[9,88]$ it nevertheless adheres to current medical terminology and practice i.e. by the terms hyper- or hypo- e.g. hyperthermia and hypothermia, hyperglycaemia and hypoglycaemia, hyperventilation and hypoventilation, etc.

The existence of physiological or functional systems was first elucidated many years ago and remains a pillar of modern medicine $[6,9]$. The doctor's examination is designed to establish the nature and extent of systemic dysfunction and/or of vital signs i.e. the measurement of blood pressure, blood glucose, temperature, etc; however the advance of biomedicine has steadily displaced the physical examination with more fashionable diagnostic tests of body fluids which, it is considered, enable the doctor to establish the precise biological cause of the condition although this technique suffers from a number of inherent limitations. This reductionist paradigm has very significant limitations. The existence of the physiologically regulated functional systems is not in doubt although, perhaps, their nature, structure and significance has not hitherto been satisfactorily explained [6], recognised or accepted.

It is an essential aspect of neuroregulatory approach outlined in this article that no single entity in the brain or the viscera has a dominant role. If we remove a particular component in the brain or in the body this will influence the regulatory dynamic and ultimately the levels of morbidity and longevity experienced by the patient. Nevertheless the role of the hypothalamic centres e.g. arcuate nucleus, paraventricular nucleus, lateral hypothalamic area, etc; play a significant, if not essential, role in the management of energy homeostasis [89]. These hypothalamic centres react to a wide range of biochemical signals e.g. from sugars [90], proteins/peptides e.g. ghrelin [91,92], orexin [93], etc.

Ghrelin appears to be significant for several reasons: (i) it is secreted by the endocrine cells in the stomach, (ii) it appears to be the only protein/peptide which stimulates food intake i.e. its association with meal size, (iii) ghrelin binds to a receptor in the arcuate nucleus in the hypothalamus, (iv) that patients undergoing gastric bypass as a treatment for obesity are found to have almost undetectable levels of ghrelin [91]. Accordingly neural regulation of levels of ghrelin [91,92], or of the neural mechanisms which could influence levels of ghrelin, have immense therapeutic significance.

\section{Further evidence for a network of neurally regulated systems}

As outlined earlier, the autonomic nervous system functions in the manner of a neurally regulated and integrated network of organ 
networks however such a system cannot function in isolation from the central nervous system but must work in coordination with all other regulatory elements e.g. affecting the function of the Central Nervous System: (i) the demyelination which is characteristic of multiple sclerosis, (ii) l-dopa as a treatment for Parkinsonism, (iii) etc.

In addition, neurons in the hypothalamus act in a way which suggests that the hypothalamus receives biochemical signals and that this is associated with neural regulation of metabolic rate [94] however the hypothalamus cannot be the sole neural component which is involved in this process. It must also involve memory and sensory input i.e. in order to be significant sensory input must be compared with experiences.

The brain and neural networks have a particular function(s) i.e. to regulate the body's function. The contemporary explanation is that this involves the autonomic nervous system i.e. the sympathetic and parasympathetic nervous systems, however this excludes the possibility that the brain regulates the body's function and that this neuroregulatory mechanism comprises a structural relationship (Figure 2) which involves the coherent and/or synchronised function of the organs i.e. organ networks; and cellular and molecular biology $[14,85,86]$.

The stability of these physiological or functional systems, and consequently of changes to cellular and molecular biology, can be altered by stress which we experience via the integrated and coordinated function of the senses [95-98] however, according to various web sites and academic publications, an estimated $80-90 \%$ of sensory input is visual [99]. (An estimated $80 \%$ of the brain's activity is devoted to the processing of visual input. In the brain, there are $>10^{\wedge} 8$ neurons devoted to visual processing. This occupies circa $30 \%$ of the cortex. By comparison just $3 \%$ of the cortex is involved in hearing. Each of the optic nerves comprises circa $10^{\wedge} 6$ fibres whilst each auditory nerve carries circa 30,000 fibres).

Accordingly sensory input can be positive or negative - both have biological correlates. Positive sensory input stimulates the immune system, raises levels of endorphins, increases our vitality, improves our mood, etc. It makes us feel good. By contrast, negative sensory input is what we recognise as stress. It lowers the immune response (which involves the spleen, thymus, bone marrow, intestines, lymph glands, etc), raises our susceptibility to infection, slows our recovery from illness or injury, reduces the ability to concentrate, lowers our mood, etc. [100]. It has biological correlates. It influences our systemic stability e.g. the quality and quantity of sleep, regulation of blood pressure and blood glucose, feelings of appetite and satedness, the function of the intestines and subsequently the quality of excrement, the frequency of urination, the smooth function of the lungs, regulation of acidity, menstrual cycle, etc. The development of pathological manifestations to cellular and molecular biochemistry is the consequence of this instability.

In recognition of these phenomena a number of tests [101-106] have been developed which attempt to quantify the level of autonomic dysfunction e.g. Stress-testing, Valsalva test, Tilt table test, etc; however these tests are experiential. They lack a coherent theoretical understanding of the phenomena i.e. how the brain regulates the autonomic nervous system.

Light is the mechanism which enables us to visualise our environment and hence experience positive and negative life experiences. It offers us a mechanism to understand in greater detail the function of the autonomic nervous system.

\section{The Physiological Significance of Light}

Although light is the most dominant of the senses, in terms of its overall function, its effect should not be considered in isolation $[95,96]$. The brain assesses the complex and coordinated effect of sensory input from its surrounding environment in its efforts to sustain its stability and function e.g. to determine behaviour. Light conveys one person's behaviour to others in more detail than any other sensory modality. Nevertheless, as highlighted in this article, the effect of light upon the body's function is not solely visual. Light performs a function which is significantly more complex than just conveying pictures of our environment to the brain.

\section{Colour perception as a diagnostic modality}

Light has been used as a therapeutic modality since the time of the Pharoahs. It has been incorporated into various forms of 'light therapy' however despite the apparent lack of scientific explanation for the role performed by light, in particular its influence upon the body's function, there is not yet a recognition of how light influences the body's function.

Light influences the function of the autonomic nervous system e.g. the colour red stimulates the sympathetic nervous system whilst the colour green influences the parasympathetic nervous system [107-109].

If the phenomena of 'changes of colour perception' were associated solely with the function of the retina, colour perception would be linked to the number of retinal photoreceptors/opsins however this has been shown not to be so [110]. In addition it has been identified that, in addition to the visual perception of our environment, light is able to stimulate the brain by a non-retinal mechanism [111].

There is a fundamental phenomenon which, if understood, can be adapted and used to better understand the function of the autonomic nervous system. Drugs which raise or lower our heart rate influence our colour perception [112]. By contrast, the walls of a heart ward in secondary care are often painted a light shade of green because this colour appears to slow the function of the heart, reduces heart rate and enables the heart to more effectively recover its normal regulated function [113]. Patients who are exposed to a natural environment [113-118] recover more quickly than those who remain in an artificial environment [119]. Our behaviour and by implication our physiology, is continuously influenced by the sensory input which we continuously receive from our environment [117].

Changes of colour perception are a feature of all biological changes $[14,15,100,120,121]$ including all drugs, viruses, vaccines, and medical conditions; although it is in the diabetic where there have been the greatest amounts of research. In diabetes, changes of colour perception are a feature of the onset of diabetes from its earliest pre-symptomatic onset $[1,122]$. This research suggests that, at least in the case of diabetes, such changes of colour perception are associated with the earliest onset of diabetes [123,124], the levels of insulin and/or blood glucose, and/or the production of highly bioluminescent glycated proteins $[125,126]$.

The development of type 2 diabetes is now measured by determining the levels of glycated haemoglobin although glycated insulin would appear to have been a more logical choice. Insulin has a relatively low half-life which may have made the selection of glycated insulin more problematic. In addition there is a wide range of proteins which have been converted to glycated analogues (albumin, LDL-cholesterol, 
etc). The HbAlc test assumes that the level of these glycated proteins remains relatively stable.

When measuring the proportion of a protein in histopathological testing how much of the protein is physiologically significant? Proteins continuously change their shape according to the conditions which exist in the prevailing biological environment. They can be coiled and reactive or uncoiled and unreactive e.g. (i) there may be a high level of a protein (insulin) but low level of protein reactivity or (ii) there may be a low level of a protein (insulin) but a high level of protein reactivity. This is typical of type 2 and type 1 diabetes respectively. It explains why someone with type 2 diabetes could be prescribed insulin which is the recognised treatment for type 1 diabetes. The assumption that the level of a single biochemical can be used as a precise determinant of pathology is therefore an inherently flawed assumption $[127,128]$. In addition most medical conditions have complex polygenomic, multisystemic basis with varying degrees of co-morbidities [129]. There are often ranges of presenting pathologies of different significance. Accordingly there is scope for significant inaccuracies by the biomarker approach.

Also, the influence of genotype and phenotype must both be considered. There are two main options to consider: (i) that we are able to identify and measure how much of the protein is reactive-which must be influenced by the prevailing cellular medium; and/or (ii) that we measure the rate at which the protein reacts.

Almost all medical conditions, viruses, vaccines and drugs are accompanied by changes to colour perception $[14,15,100,112]$. Changes of colour perception are a feature of type 1 and type 2 diabetes therefore changes of colour perception are a feature of genotype and phenotype. The prescribing of insulin temporarily alters colour perception. Furthermore the onset of changes to colour perception occurs from the presymptomatic stage [121-124]. These observations illustrate that changes of colour perception are a fundamental and significant feature of the body's biology i.e. changes of colour perception have pathological origins. This can be explained by noting that most proteins are visually active [130-136]. They absorb and release light. This phenomenon is commonly known as 'bioluminescence'. The spectrum and intensity of the light, in particular of the biophotons of light which are released, influences colour perception and is a direct measure of rate of reaction. It is a precise marker of presenting pathology. It effectively creates a digital format, or common denominator, upon which to develop a personal bio-mathematical model of the autonomic nervous system.

That drugs, viruses, pathologies, vaccines and other bioactive substrates influence colour perception supports the view that changes of colour perception have biological origins which affect retinal function however light influences the body's function through the eyes and the skin i.e. there is more than one biological mechanism. Such is the complexity of the body's function that it is pertinent to consider that these two mechanisms may not be the sole mechanism to explain the phenomena of colour perception e.g. the observation, as studied in optogenetics, that neurons may be stimulated by light illustrates that a non-retinal mechanism may also be viable [111].

This phenomenon of changes to colour perception was first recognised and investigated by Spittler in the 1930's [108]. It forms the basis of the discipline known as Syntonic Optometry. In recent years a number of patents have been registered re medical devices or techniques which have sought to adapt this phenomenon to diagnose blood glucose levels.

\section{Light and colour as a therapeutic modality}

Sensory input influences the regulated function of the autonomic nervous system and physiological systems. Accordingly, at least in principle, the correct selection of sensory input, irrespective of the sensory modality, must also have therapeutic significance. As stated earlier an estimated $80-90 \%$ of sensory input is visual therefore light may also have significant potential as a therapeutic modality depending upon the nature and origins of the medical condition. Exposure to stress creates a predisposition to a medical condition [136-139] therefore the removal of the stress has the potential to reduce or remove this predisposition or actual disposition to a medical condition however the issue is clearly far more complex. If the stress has significant magnitude or longevity this creates a memory which influences the stability of the autonomic nervous system including our function and health.

The function of light has been immensely underestimated and overlooked by the vast bulk of medical research. It conveys the majority of data which enables us to connect and interact with our environment but sensory input (of which $80-90 \%$ is visual/light) is also an essential component for life and/or for normal mental and/or physiological development [135]. Light has been shown to have the potential to change the way that the brain sustains memories [137] and control gene expression [138]. It plays an essential role stimulating the body's immune function [139]; it influences the regulated function of the heart $[140,141]$ the liver $[141,142]$, the skin [141], the brain [142], the pituitary gland [143], etc. Exposure to light stimulates the production of vitamin D [144] which influences the immune response and hence our susceptibility to a wide range of medical conditions [143]. Over one hundred medical conditions are known to respond to the therapeutic effect of light e.g. depression [144-148], migraine [149], psoriasis [141], diabetes [150,151], faster healing of diabetic fibroblast cells [152], hyperbilirubinaema [153,154], attention-deficit hyperactivity disorder [155], dyslexia [156], premenstrual syndrome [157], etc.

Nevertheless every light therapy is not the same (so it is not possible to apply a meta-analysis of existing data). There is not yet an accepted understanding of the phenomena therefore the simplistic application of light is fraught with difficulties. The random flashing of lights could stimulate a photosensitive event e.g. a migraine, yet techniques based upon this principle [158] have been approved for use as a treatment for migraines [149]. There is a significant scientific principle involved.

The current level of understanding appears to be based upon the concept of 'heart-rate variability' i.e. the time interval between heartbeats, but it excludes any understanding of how the brain, and the EEG frequencies in particular, regulates or influences the body's multi-level function. Accordingly it is completely unrealistic to expect that the results from clinical studies, based upon an incomplete understanding of the phenomena, can give an optimum physiological response. Nevertheless light-based biofeedback, neurofeedback and laser-based techniques have become widely used for the treatment of a range of conditions including psoriasis, seasonal-affective disorder, hyperbilirubinaemia, dyslexia.

In addition there is evidence that such techniques may be effective in treating a range of medical conditions including diabetic leg ulcers $[159,160]$, pancreatic cancer [161], etc.

It has taken a great deal of time for the person to become unwell. Accordingly it is unreasonable to expect instantaneous relief. Nevertheless this illustrates the essential distinction between medications and the sensory approach. Medication alleviates the symptoms of dysfunction but does little, if anything, to alleviate the 
fundamental cause of the condition. It is for this reason that most migraine medications are poorly effective at preventing the onset of migraines. They can offer deliver rapid relief from symptoms and it is for this reason that drugs are widely used. They alter the dynamic relationship between sensory input, neural regulation and organ dysfunction however it is for this reason that drugs often become ineffective over a period of use i.e. the brain starts to compensate for the biological changes which have been induced by the medication.

This illustrates the functional relationship which exists between sensory input and the autonomic nervous system and, in particular, how the function of the brain is (i) continuously receiving and processing multi-sensory data, (ii) comparing this data with an extensive bank of memories; and (iii) using this information to continuously regulate the body's stability and that of the physiological systems (Figure 1). Failures of this mechanism i.e. of autonomic dysfunction result in the emergence of pathologies which influence the function of the brain and its subsequent ability to regulate the autonomic nervous system and physiological systems (Figure 2). The basic biological reactions are altered due to a shortage of substrates, co-factors and/or by changes to the prevailing reaction conditions. This is a fundamental feature of the laws of chemistry and of reaction kinetics which apply to every chemical reaction (Figure 3).

All chemical reactions in the body must comply with the basic laws of chemistry. This applies to

(i) the expression of proteins by the genes-which must therefore be influenced by acidity and temperature,

(ii) the expressed protein-which may be coiled and reactive or uncoiled and unreactive,

(iii) the subsequent downstream reactions. The term insulin resistance' has become the accepted term to explain type 2 diabetes yet there is no such term as 'resistance' in chemistry. Either a chemical reacts or it does not react. The term 'insulin resistance' is a distraction. The problem of diabetes is the inability of insulin to react with its reactive substrate - the insulin receptor protein (IRP) - and that this is a $\mathrm{pH}$ and/or Magnesium dependent reaction.

(iv) the protein absorbs energy in order to attain its reactive state whereupon it reacts with its reactive substrate and releases energy, in the form of light, which has a particular frequency(colour) and intensity.

This applies to the genetic expression of proteins and/or to the reaction of the expressed protein with its reactive substrate(s). The biochemical which we measure as biomarkers for a particular disease are often the consequences of this process i.e. of autonomic dysfunction, yet we can alter the body's function by providing biological changes through nutrition or drugs. Each alters colour perception to a greater or lesser degree. Significantly these involve the visceral organs in the digestive system so the body's function is influenced by both sensory and visceral input. Moreover, as outlined earlier, the use of drugs is an artificial construct. They disrupt the mechanism by which the brain regulates the autonomic nervous system. Most drugs are poisonous entities unless used at the prescribed levels. If used at a level which

[Reaction Conditions]

Energy $+\mathrm{A}+\mathrm{B} \longrightarrow \mathrm{C}+\mathrm{D}$ (metabolites) + Energy

Figure 3: Reaction Kinetics is lower than advised the drug often becomes ineffective. If used at too high a level the drug may be toxic or lead to drug side-effects. Accordingly the body's function and the onset of pathologies may have sensory-neural and/or visceral origins.

Often a drug will influence other physiological systems e.g. a betablocker (atenolol) may be co-prescribed with a diuretic (chlorthalidone) in order to slow the beat of the heart and reduce blood volume i.e. the effect of the beta-blocker upon heart function needs to be compensated by a reduction in circulatory blood volume. Someone who is prescribed a drug which lowers their metabolic rate will start to gain weight i.e. the drug interferes with the neural regulation of system function. It also interferes with the broad range of sensory input/perception e.g. appetite or satiety, hearing spectrum, colour perception, etc. Accordingly someone with a particular medical condition, who may or may not be receiving drugs to treat the condition, may find that their feelings of appetite or satedness may be affected e.g. they lose their appetite, have lower energy, become increasingly depressed (lower mood), exercise too little, or eat too much.

\section{Adapting the mechanisms which influence system function}

The body's function can be influenced in different ways e.g. by the electrical currents in neural stimulation, smell and/or taste; sound and vibration; frequency-based mechanisms involving light and sound; meditation; touch; changes of gravity, temperature, air quality and/ or pressure/altitude; acupuncture meridians; etc. Each influences the body's function by influencing different aspects of the regulatory mechanism. That such factors influence the body's function is not in doubt however what needs to be clarified is whether such phenomena can be adapted and, if so, the extent to which these observations can be adapted with therapeutic effect [162].

The mechanisms for these therapeutic modalities can be divided into two categories i.e. feed forward and feedback. Most of this article has been devoted to the discussion of the feed forward mechanism in which information received via the senses is processed by the brain and subsequently influences systemic stability, organ function, and cellular and molecular biology [85]; however in a dynamic biological system there must also be a feedback mechanism providing information about all parts of the body's functional abilities to the brain. This is illustrated by noting the declining effectiveness of drugs over a period of time i.e. as the brain compensates for biological change in its efforts to maintain and optimise physiological stability. Further evidence of this process is the occurrence of drug side-effects and of adverse effects e.g. weightgain, which accompanies the use of anti-depressives or tranquillisers.

That acupuncture can be immensely effective e.g. enabling a surgeon to conduct open-heart surgery without anaesthesia, illustrates the existence of a biofeedback mechanism in which stimulation of the acupuncture meridians in various ways (by needles, pressure, light, and by pharmacological agents) stimulates biological changes e.g. of neuro-peptides, which influence the ability of the brain to regulate the body's function. This is part of the complex mechanism which has been adapted by pharmaceutical companies to deliver drugs. It illustrates why drugs are only circa $50 \%$ effective [26] i.e. because drugs treat the consequences of autonomic dysfunction and yet do little to influence the fundamental cause of the condition. By comparison initial studies have indicated that Strannik Light Therapy may be up to $93.2 \%$ effective [163].

As stated earlier, the understanding of this mechanism enables the surgeon to conduct open-heart surgery without the need for 
anaesthetics. It is an immensely powerful phenomenon which has been adapted with diagnostic and therapeutic effect. There are various medical devices which are based upon determining which acupuncture meridians are dysfunctional and which can be stimulated by light, pressure or an electrical impulse to give a therapeutic response and/ or to eliminate the pain response. Nevertheless the theoretical understanding of such techniques has not yet been fully elucidated [164]. Consequently the reliability and effectiveness of such techniques remains controversial. (This illustrates a common failure of medicine and medical research i.e. to reject a technology or phenomena because the results are unsatisfactory rather than to understand why the phenomenon is effective in some patients). Although used to treat a wide range of ailments there is not yet an extensive body of evidence to support the widespread use of such devices. In addition, the quality of such techniques is often heavily dependent upon the expertise, calibre and abilities of the practitioner.

\section{Does one person's health influence the health and function of others?}

The mechanism outlined (Figure 4) also influences our behaviour. In effect one person's sensory output i.e. their behaviour, is another person's sensory input e.g. as a person yawns and influences other people to yawn. Our behaviour can have a positive or negative effect upon those around us i.e. stress can have interpersonal origins e.g. in the home-from family or friends, or in the workplace-from our colleagues.

This is further evidence that our ability to recover from a disease or medical condition can be influenced by the data flow from our environment e.g. (i) whether the attitude of the carer projects a positive or negative message to their patient, (ii) if the doctor gives a positive or negative message to the patient [165], (iii) if the nurse(s) have a caring demeanour [166-171], and (iv) if the environment in which the patient is being treated is able to stimulate their recovery [172-182] e.g. by light/colour, sound/noise, nutrition, smell, etc.

We plan our lives around the key aspects of our function and hence the pursuit of functional system stability: the supply of food and drink, heat and shelter, sleep and procreation i.e. the brain regulates blood glucose-our blood glucose level starts to decline-we become hungrythe brain decides to seek out a supply of food with an increasing sense or degree of urgency-etc. This illustrates that there is a link between the brain's Executive functions, the input of sensory data, and the regulated function of the autonomic nervous system and physiological systems although there is not yet any recognition by the research community of the mechanism which the brain uses to regulate the body's function. This is ably summarised as follows:

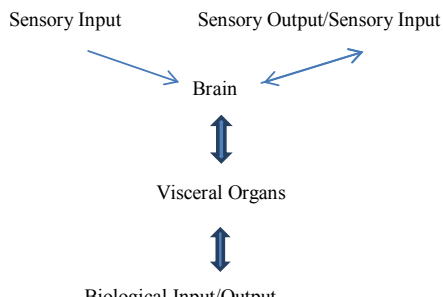

Biological Input/Output

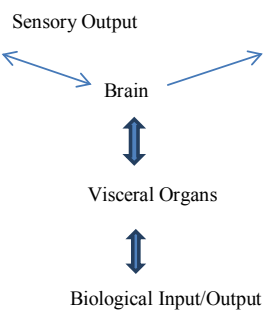

Figure 4: How One Person's Sensory Output is Another Person's Sensory Input.
"If you take an airplane, a Boeing 777, I think it has like 100,000 parts. If I gave you a parts list for the Boeing 777, in one sense you'd know a lot. You'd know 100,000 components that have got to be there, screws and wires and rudders and things like that. On the other hand, I bet you wouldn't know how to put it together. And I bet you wouldn't know why it flies. Well, we're in the same boat. We now have a parts list. That's what the Human Genome Project is about is getting a parts list. If you want to understand the plane, you have to have the parts list, but that's not enough to understand why it flies" Lander E [183].

In order to understand how the body functions we have to consider the available evidence.

\section{The Brain Uses Frequency to Regulate the Body's Stability and Function}

The use of electroencephalograph (EEG) to determine abnormalities of brain function or of magnetic resonance imaging (MRI) to determine changes of brain structure or neural blood flow are widespread. The EEG in particular determines changes to neural frequencies however, despite the immense amount of research regarding this phenomenon, there is not yet an accepted opinion of what, precisely, is the function of the brain or the role of the EEG frequencies. Changes of EEG are considered to be the consequence of neural structure and biochemistries yet there is a body of evidence which suggests that EEG frequencies are fundamental aspects of brain function [8]; that cognitive input influences neural function; that the fundamental function of the brain is to continuously regulate the body's stability $[5,8,10,12]$; and that it does so by employing a frequency-based mechanism.

The theta and delta frequencies function throughout the full 24 hour cycle. There are absolutely no examples of people continuing to live their lives without an adequately functioning brain and/or without the existence of theta and, in particular, delta frequencies. The loss of part of the cerebrum, cerebellum or amygdala impairs a patient's function and quality of life. Accordingly the evidence illustrates that (i) the beta and alpha frequencies are associated with normal cognitive processes whilst (ii) the theta and delta frequencies function at a more physiologically significant level and are essential features of the body's function including the fixation of memories. The evidence is further strengthened by noting how patients with severe brain injuries may enter a comatose state in which the delta frequency is dominant and that our sleep comprises cycles of typically 90 minutes duration in which the theta and delta (mainly delta) frequencies predominate.

There is an ever greater level of understanding of how sensory input influences the body's function and, in particular, how frequency plays a significant role in this process. It is evident that the body's function involves the coordinated function of different biological cycles. There is evidence of biological cycles which influence almost every aspect of the body's function. Changes at puberty (at circa 12-15 years), pregnancy (typically 9 months), menstruation (typically for several days in every 28 day period), the circadian sleep cycle (typically 7-8 hours in every 24 hours), the release of insulin (typically 6-15 minutes) and many ultradian cycles e.g. the release of Growth Hormone by the hypothalamus, the thyroid takes several hours to respond to the release of Thyroid Stimulating Hormone by the pituitary gland, etc; are evidence of biologically significant changes which affect the long and short term regulation of the body's function [184]. Perhaps such long cycles are necessary because of the low rate of production of specific hormones. Furthermore the length of such cycles is often influenced by the patient's medical condition and/or their environment [185]. 
Accordingly where is the evidence for the control mechanisms which regulates these complex structural relationships?

The onset of puberty may occur earlier or later, a pregnancy may be early or late, the menstrual period may be shorter or longer, the duration and intensity of sleep may shorten, the cyclic release of insulin may be significantly longer than the normal 6 minutes, etc.

We are drawn to consider that the sole function of the brain is the continuous regulation of the body's physiological stability $[3,5]$ and that frequency plays a significant role in this mechanism i.e. to regulate systemic stability. The brain regulates systemic stability by a biophysical mechanism yet its function is influenced by its biology. Support for this hypothesis comes from the existence of a developed and commercialised software technology-Strannik Virtual Scanning [186,187] and Strannik Light Therapy $[8,188,189]$ in which the patient-specific frequencybased light therapy involves the selection of a number of parameters including, and in particular, the specific physiological system which has been determined to be most dysfunctional.

Strannik technologies $[190,191]$ originated from a programme of research conducted by I.G.Grakov [84] at the University of Novosibirsk in the early 1980's. It involved researching the medical applications of industrial lasers. It is from the observation of a biological response to a waveform that this technology has evolved.

There is evidence to support the above hypothesis e.g. flashing lights can induce photosensitivity (migraine, epilepsy) yet flashing light therapies have been approved which treat migraine [192], dyslexia $[193,194]$, etc. Biofeedback techniques are used to treat a wide range of ailments. They are based upon the delivery of light and sound although the fundamental scientific literature which supports the use of such technologies remains vague and insubstantial i.e. such techniques are largely experiential and lack a fundamental theoretical understanding of the phenomena [195]. By contrast, Strannik Light Therapy has been used to successfully treat a wide range of ailments including sleep apnoea [196], migraine [192], dysarthria [197], headaches [198], sleep problems [198], circulatory problems [198], breathing problems [198] etc.

In the same way that pathological changes influence sensory coordination e.g. in developmental dyslexia and autistic spectrum disorders, then so too must pathological changes influence the coordinated function of the physiological systems.

\section{Summary/Evidence of a Mathematical Model of the Autonomic Nervous System and Physiological System}

Complex systems are regulated systems. They cannot be otherwise. There is evidence of an integral relationship involving the neural networks, autonomic nervous system and the physiological/functional systems. The neural networks must be physiologically significant [7]. They cannot be otherwise. There is evidence of a dynamic relationship between the function of the brain and visceral organs which involves a structured relationship involving the physiological systems [3$5,8,12,14]$, endocrine glands, and (at the visceral level) changes to cellular \& molecular biology. There is also evidence that light/colour influences the function of the autonomic nervous system and hence that changes of colour perception have a biological basis (i.e. with genetic and phenotypic origins); and there is evidence that stress has pathological correlates [199].

Such observations, supported by the existence of Grakov's Strannik technology (Strannik Virtual Scanning and Strannik Light
Therapy) $[167,200]$ illustrates that the brain employs frequency to regulate the body's function i.e. to modulate the function of the various physiological systems [201-204] e.g. blood glucose, blood pressure, sleep, temperature, acidity, digestion, etc. Biological change at the cellular \& molecular level is often the consequence of systemic dysfunction. The biological entity that is the brain regulates the body's stability by a biophysical, frequency-based mechanism and is influenced by a biological feedback mechanism which involves memory $[26,205]$. Depending upon circumstances i.e. the fundamental cause of a medical condition, there may be two or three pathways by which the body's function is altered:

(i) the top-down pathway in which changes of systemic stability for example arising from the influence of stress influence the function of the organs; changes of organ function influence cell biology; and changes of cell biology influence molecular biology. This is the mechanism used by psychologists, neurologists, and various types of Complementary and Alternative Techniques. It is how stress influences the body's function.

(ii) the bottom-up pathway in which changes of molecular biology influence cell biology; changes of cell biology influence organ function; and changes of organ function influence systemic stability. This is the mechanism by which drugs are used to alter the body's function.

(iii) the dynamic relationship i.e. molecular biology has two facets which have equal significance: genotype and phenotype; and which function in an interconnected manner. In general, genotype and phenotype do not function in isolation.

Grakov's research, which has elucidated the relationship between genotype and phenotype, illustrates the relationship between psychology and physiology. Psychology is effectively the study of phenotype i.e. the greatest source of stress which we experience in outlives comes from the stresses and strains of inter-personal relationships (Figure 4). It studies the behavioural consequences of our biochemistry. The most severe stresses e.g. the termination of a close relationship/or divorce, of being over-looked for promotion [206,207], the failure of a business venture [208], the death of a loved-one [209], of loneliness [209]; have pathological correlates which influence our subsequent health and behaviour. By contrast our genetic profile establishes the general traits which characterise our personality and our subsequent behaviour. This is the rational and/or emotional elements of behaviour which have perplexed the psychologist for centuries.

The idea that the brain's function could be influenced or regulated by frequency is not new. The idea or neural coherence or synchronisation has been debated for the last 20-30 years, perhaps since Bullock's research, however it is only in the last 10-20 years that an accumulating body of evidence has emerged illustrating the coherence of opinions i.e. that neural networks work in a synchronised manner [193]; that this involves cognitive input [96-98], the autonomic nervous system $[14,15,205]$, a mathematical relationship involving organ systems, organs, cells and molecular biology [14,15,45,118], the physiological or functional systems $[1,8,12,14,15,19,69,87,187]$; and that each physiological or functional system has a behavioural $[118,136]$ or 'executive' significance $[7,136]$.

As we age, we become less willing to accept change. We make our decisions based upon what we have seen or done in our lives. This reflects the underlying hypothesis which is set out in this article. The limits of our function, and hence of the autonomic nervous system and our mental and physical health, are influenced by our cellular and molecular biology including age, weight and gender. 
Citation: Ewing GW (2015) The Framework of a Mathematical Model of the Autonomic Nervous System and Physiological Systems: Using the Neuroregulation of Blood Glucose as an Example. J Comput Sci Syst Biol 8: 059-073. doi:10.4172/jcsb.1000172

\section{Acknowledgement}

This article is based upon the research of the medical doctor, physicist and mathematician Igor Gennadyevich Grakov Ph.D. which was undertaken during his tenure as a researcher at the University of Novosibirsk in the early 1980's. This research was initially based upon the medical application of industrial lasers. It led to the observation of a biological response to a waveform which serves as the basis for the biomathematical model upon which the Strannik technologies are based. My thanks to $\mathrm{Dr}$ Grakov and the many researchers including Yulia Borovleva Ph.D. who through their work have directly and indirectly contributed to the successful development of this technology.

\section{References}

1. Ewing GW, Grakov IG (2013) A Further Review of the Genetic and Phenotypic Nature of Diabetes Mellitus. Case Reports in Clinical Medicine 2: 538-553.

2. Melloul D, Marshak S, Cerasi E (2002) Regulation of insulin gene transcription Diabetologia 45: 309-326.

3. Marks AR (2008) Physiological systems under pressure. J Clin Invest 118: 411 412.

4. Ewing GW, Ewing EN (2008) NeuroRegulation of the Physiological Systems by the Autonomic Nervous System-their relationship to Insulin Resistance and Metabolic Syndrome. Biogenic Amines 22: 208-239.

5. St Clair Gibson A, Goedecke JH, Harley YX, Myers LJ, Lambert MI, et al. (2005) Metabolic setpoint control mechanisms in different physiological systems at rest and during exercise. J Theor Biol 236: 60-72.

6. Ewing G (2013) Virtual Scanning: a New Medical Paradigm? J Comput Sci Syst Biol 6: 93-98.

7. Niendam TA, Laird AR, Ray KL, Dean YM, Glahn DC, et al. (2012) Metaanalytic evidence for a Superordinate Cognitive Control Network subserving diverse Executive Functions. Cogn Affect Behav Neuro Sci 12: 241-268.

8. Ewing GW (2009) A Theoretical Framework for Photosensitivity: Evidence of Systemic Regulation. J Comput Sci Syst Biol 2: 287-297.

9. The Merck Manual of Medical Information

10. Saltykov AB (2009) Self-organization of physiological, pathological and ambivalent functional systems. Patol Fiziol Eksp Ter 8-13.

11. Ofer R, Stephen CB, Deborah JC (2007) Neuroregulation of appetite. Contemporary Endocrinology: Treatment of the Obese Patient 3-26.

12. Sudakov KV (2011) From molecules and genes to functional systems. Pato Fiziol Eksp Ter 3-6.

13. Clark CM, Jacova C, Klonoff H, Kremer B, Hayden M, et al. (1997) Pathological association and dissociation of functional systems in multiple sclerosis and Huntington's disease. J Clin Exp Neuropsychol 19: 63-76.

14. Ewing GW, Ewing EN (2008) Cognition, the Autonomic Nervous System and the Physiological Systems. Biogenic Amines 22:140-163.

15. Ewing GW, Parvez SH (2010) The Dynamic Relationship between Cognition, the Physiological Systems, and Cellular and Molecular Biochemistry: a Systems-based Perspective on the Processes of Pathology. Act Nerv Super Rediviva 52: 29-36.

16. Janig W (2009) The Integrative Action of the Autonomic Nervous System. Cambridge University Press.

17. Arab L, Sadeghi R, Walker DG, Lue LF, Sabbagh MN (2011) Consequences of Aberrant Insulin Regulation in the Brain: Can Treating Diabetes be Effective for Alzheimer's Disease. Curr Neuropharmacol 9: 693-705.

18. Wu PH, Giri A, Sun SX, Wirtz D (2014) Three-dimensional cell migration does not follow a random walk. Proc Natl Acad Sci USA 111: 3949-3954.

19. Ewing GW, Parvez HS (2011) Mathematical modelling the systemic regulation of blood glucose: 'a top-down' systems biology approach. Neuro Endocrinol Lett 32: 371-379.

20. Hellman B, Gylfe E, Grapengiesser E, Dansk H, Salehi A (2007) Insulin oscillations--clinically important rhythm. Antidiabetics should increase the pulsative component of the insulin release. Lakartidningen 104: 2236-2239.

21. Bengoetxea H, Ortuzar N, Bulnes S, Rico-Barrio I, Lafuente JV, et al. (2012) Enriched and deprived sensory experience induces structural changes and rewires connectivity during the postnatal development of the brain. Neural Plast 2012: 305693

22. Alwis DS, Rajan R (2014) Environmental enrichment and the sensory brain the role of enrichment in remediating brain injury. Front Syst Neurosci 8: 156.

23. Ewing GW, Ewing EN, Parvez SH (2009) The Multi-systemic Origins of Migraine. Biogenic Amines 23: 1-52

24. Thibodeau JT, Turer AT, Gualano SK, Ayers CR, Velez-Martinez M, et al. (2014) Characterization of a novel symptom of advanced heart failure: bendopnea. JACC Heart Fail 2: 24-31.

25. Below JE, Cade BE, Aguilar D, Brown E, Hanis CL, et al. (2014) Genome wide Association and Exome Sequence Data Analysis for More Than 100 Traits in Mexican Americans. Presented at American Society of Human Genetics 2014 Annual Meeting. San Diego, Calif.

26. Spear BB, Heath-Chiozzi M, Huff J (2001) Clinical application of pharmacogenetics. Trends Mol Med 7: 201-204.

27. Ewing GW, Parvez SH (2010) The multi-systemic nature of diabetes mellitus: Genotype or phenotype? N Am J Med Sci 2: 444-456.

28. Ewing GW (2013) The 'Biology of Systems' or the 'Systems of Biology': Looking at Diabetes from the Systemic Perspective. International Journal of Systems Biology 4: 45-56

29. Jaspal SK, Saleheen D, Sim X, Sehmi J, Zhang W, et al. (2011) Genomewide association study in people of South Asian ancestry identifies six nove susceptibility loci for Type 2 Diabetes. Nature Genetics 43: 984-989.

30. Bodhini D, Radha V, Ghosh S, Majumder PP, Mohan V (2011) Lack of association of PTPN1 gene polymorphisms with type 2 diabetes in south Indians. J Genet 90: 323-326.

31. Lindholm ME, Marabita F, Gomez-Cabrero D, Rundqvist H, Ekstrom TJ, et al. (2014) An Integrative Analysis Reveals Co-ordinated Reprogramming of the Epigenome and the Transcriptome in Human Skeletal Muscle after Training. Epigenetics

32. Jones S (2009) Genetic 'magic bullet' cures have proven a 'false dawn'. The Telegraph.

33. Barrès R, Yan J, Egan B, Treebak JT, Rasmussen M, et al. (2012) Acute exercise remodels promoter methylation in human skeletal muscle. Cell Metab 15: $405-411$.

34. Filippi CM, von Herrath MG (2008) Viral trigger for type 1 diabetes: pros and cons. Diabetes 57: 2863-2871.

35. Hyöty H, Taylor KW (2002) The role of viruses in human diabetes. Diabetologia 45: 1353-1361.

36. Honeyman MC, Stone NL, Harrison LC (1998) T-cell epitopes in type 1 diabetes autoantigen tyrosine phosphatase IA-2: potential for mimicry with rotavirus and other environmental agents. Mol Med 4: 231-239.

37. Honeyman MC, Coulson BS, Stone NL, Gellert SA, Goldwater PN, et al. (2000) Association between rotavirus infection and pancreatic islet autoimmunity in children at risk of developing type 1 diabetes. Diabetes 49: 1319-1324.

38. Hyöty H, Leinikki P, Reunanen A, llonen J, Surcel HM, et al. (1988) Mumps infections in the etiology of type 1 (insulin-dependent) diabetes. Diabetes Res 9: $111-116$.

39. Pak CY, Eun HM, McArthur RG, Yoon JW (1988)Association of cytomegalovirus infection with autoimmune type 1 diabetes. Lancet 2: 1-4

40. Forrest JM, Menser MA, Burgess JA (1971) High frequency of diabetes mellitus in young adults with congenital rubella. Lancet 2: 332-334.

41. Menser MA, Forrest JM, Bransby RD (1978) Rubella infection and diabetes mellitus. Lancet 1: 57-60.

42. Devendra D, Liu E, Eisenbarth GS (2004) Type 1 diabetes: recent developments. BMJ 328: 750-754.

43. Tuomilehto J, Rewers M, Reunanen A, Lounamaa P, Lounamaa R, et al. (1991) Increasing trend in type 1 (insulin-dependent) diabetes mellitus in childhood in Finland. Analysis of age, calendar time and birth cohort effects during 1965 to 1984. Diabetologia 34: 282-287.

44. Kelly HA, Russell MT, Jones TW, Byrne GC (1994) Dramatic increase in incidence of insulin dependent diabetes mellitus in Western Australia. Med $J$ Aust 161: 426-429. 
Citation: Ewing GW (2015) The Framework of a Mathematical Model of the Autonomic Nervous System and Physiological Systems: Using the Neuroregulation of Blood Glucose as an Example. J Comput Sci Syst Biol 8: 059-073. doi:10.4172/jcsb.1000172

45. Rewers M, LaPorte RE, Walczak M, Dmochowski K, Bogaczynska E (1987) Apparent epidemic of insulin-dependent diabetes mellitus in Midwestern Poland. Diabetes 36: 106-113.

46. Black PH (1994) Central nervous system-immune system interactions: psychoneuroendocrinology of stress and its immune consequences. Antimicrob Agents Chemother 38: 1-6.

47. Wang L, Lovejoy NF, Faustman DL (2012) Persistence of prolonged C-peptide production in type 1 diabetes as measured with an ultrasensitive C-peptide assay. Diabetes Care 35: 465-470.

48. Cnop M, Welsh N, Jonas JC, Jörns A, Lenzen S, et al. (2005) Mechanisms of pancreatic beta-cell death in type 1 and type 2 diabetes: many differences, few similarities. Diabetes 54 Suppl 2: S97-107.

49. Engelen W, Bouten A, De Leeuw I, De Block C (2000) Are low magnesium levels in type 1 diabetes associated with electromyographical signs of polyneuropathy? Magnes Res 13: 197-203.

50. Brilla LR (2012) Magnesium Influence on Stress and Immune Function in Exercise. J Sports Med Doping Stud 2:111.

51. Tam M, Gómez S, González-Gross M, Marcos A (2003) Possible roles of magnesium on the immune system. Eur J Clin Nutr 57: 1193-1197.

52. Geerlings SE, Hoepelman Al (1999) Immune dysfunction in patients with diabetes mellitus (DM). FEMS Immunol Med Microbiol 26: 259-265.

53. Calame KL (1985) Mechanisms that regulate immunoglobulin gene expression Annu Rev Immunol 3: 159-195.

54. Hruby A, Meigs JB, O'Donnell CJ, Jacques PF, McKeown NM (2014) Higher magnesium intake reduces risk of impaired glucose and insulin metabolism and progression from prediabetes to diabetes in middle-aged americans. Diabetes Care 37: 419-427.

55. Sjögren A, Florén $\mathrm{CH}$, Nilsson A (1986) Magnesium deficiency in IDDM related to level of glycosylated hemoglobin. Diabetes 35: 459-463.

56. Nikolic D, Stanimirovic J, Bjelogrlic P, Isenovic ER (2014) Oxidative stress and the role of antioxidative treatment in diabetes mellitus. Oxid AntiOxid Med Sci $3 \cdot 9-14$

57. Brady RO, Kanfer JN, Shapiro D (1965) Metabolism of Glucocerebrosides. Ii. Evidence of an Enzymatic Deficiency in Gaucher's Disease. Biochem Biophys Res Commun 18: 221-225.

58. Hoffmann B, Beck M, Sunder-Plassmann G, Borsini W, Ricci R, et al. (2007) Nature and prevalence of pain in Fabry disease and its response to enzyme replacement therapy - a retrospective analysis from the Fabry Outcome Survey. The Clinical Journal of Pain 23: 535-542.

59. Esquivel G, Schruers KR, Maddock RJ, Colasanti A, Griez EJ (2010) Acids in the brain: a factor in panic? J Psychopharmacol 24: 639-647.

60. Wiederkehr M, Krapf R (2001) Metabolic and endocrine effects of metabolic acidosis in humans. Swiss Med Wkly 131: 127-132.

61. Thernlund GM, Dahlquist G, Hansson K, Ivarsson SA, Ludvigsson J, et al (1995) Psychological stress and the onset of IDDM in children. Diabetes Care 18: $1323-1329$

62. Helmreich DL, Parfitt DB, Lu XY, Akil H, Watson SJ (2005) Relation between the hypothalamic-pituitary-thyroid (HPT) axis and the hypothalamic-pituitaryadrenal (HPA) axis during repeated stress. Neuroendocrinology 81: 183-192.

63. Herman JP, Figuerierdo H, Mueller NK, Ulrich-Lai Y, Ostrander MM, et al. (2003) Central mechanisms of stress integration: Hierarchical circuitry controlling hypothalamo-pituitary-adrenocortical responsiveness. Front Neuroendocrinol 24: 151-180.

64. Meerman R, Brown AJ2 (2014) When somebody loses weight, where does the fat go? BMJ 349: g7257.

65. Ranabir S, Reetu K (2011) Stress and hormones. Indian J Endocrinol Metab 15: 18-22.

66. Bradley LA, Richter JE, Pulliam TJ, Haile JM, Scarinci IC, et al. (1993) The relationship between stress and symptoms of gastroesophageal reflux: the influence of psychological factors. Am J Gastroenterol 88: 11-19.

67. McDonald-Haile J, Bradley LA, Bailey MA, Schan CA, Richter JE (1994) Relaxation training reduces symptom reports and acid exposure in patients with gastroesophageal reflux disease. Gastroenterology 107: 61-69.
68. Pang XP, Hershman JM, Mirell CJ, Pekary AE (1989) Impairment of hypothalamic-pituitary-thyroid function in rats treated with human recombinan tumor necrosis factor-alpha (cachectin). Endocrinology 125: 76-84.

69. Ewing GW (2012) pH is a Neurally Regulated Physiological System. Increased Acidity alters Protein Conformation and Cell Morphology and is a Significan Factor in the onset of Diabetes and other common pathologies. The Open Systems Biology Journal 5: 1-12.

70. Sigel, Astrid Sigel, Helmut Sigel, Roland KO (2013) Interrelations between Essential Metal lons and Human Diseases. Metal Ions in Life Sciences 13 $1-573$

71. Sinclair LM, Hinton PS (2005) Prevalence of iron deficiency with and withou anemia in recreationally active men and women. J Am Diet Assoc 105: 975978.

72. Densmore JJ (2008) Inherited and acquired hematologic disorders in athletes. Clin Adv Hematol Oncol 6: 111-112.

73. Dubnov G, Constantini NW (2004) Prevalence of iron depletion and anemia in top-level basketball players. Int J Sport Nutr Exerc Metab 14: 30-37.

74. Kaiser U, Barth N (2001) Haemolytic anaemia in a patient with anorexia nervosa. Acta Haematol 106: 133-135.

75. Kennedy A, Kohn M, Lammi A, Clarke S (2004) Iron status and haematological changes in adolescent female inpatients with anorexia nervosa. J Paediat Child Health 40: 430-432.

76. Polonsky KS, Given BD, Hirsch LJ, Tillil H, Shapiro ET, et al. (1988) Abnorma patterns of insulin secretion in non-insulin-dependent diabetes mellitus. N Eng J Med 318: 1231-1239.

77. Orci L, Malaisse-Lagae F, Ravazzola M, Rouiller D, Renold AE, et al. (1975) A morphological basis for intercellular communication between alpha- and betacells in the endocrine pancreas. J Clin Invest 56: 1066-1070.

78. Iliff JJ, Wang M, Liao Y, Plogg BA, Peng W, et al. (2012) A Paravascular Pathway Facilitates CSF Flow Through the Brain Parenchyma and the Clearance of Interstitial Solutes, Including Amyloid $\beta$. Sci Transl Med 4: 147 ra111.

79. Severs NJ (2000) The cardiac muscle cell. Bioessays 22: 188-199.

80. Kordon C, Bihoreau C (1989) Integrated communication between the nervous endocrine and immune systems. Horm Res 31: 100-104.

81. Scherer T, O'Hare J, Diggs-Andrews K, Schweiger M, Cheng B, et al. (2011) Brain insulin controls adipose tissue lipolysis and lipogenesis. Cell Metab 13 183-194.

82. Booth FW, Chakravarthy M, Spangenburg EE (2002) Exercise and gene expression: physiological regulation of the human genome through physical activity. J Physiol 543: 399-411.

83. Legg MJ (2011) What is psychosocial care and how can nurses better provide it to adult oncology patients. Australian Journal of Advanced Nursing 28: 61-67.

84. Grakov IG (1985) Strannik Diagnostic and Treatment System: a Virtual Scanner for the Health Service. Minutes of Meeting No. 11 of the Praesidium of the Siberian of the Academy of Medical Sciences of the USSR (AMN) held in Novosibirsk 4 December 1985

85. Kandel E (2006) The New Science of Mind. Scientific American Mind 17: 62-69.

86. Noble D (2008) Claude Bernard, the first systems biologist, and the future of physiology. Exp Physiol 93: 16-26

87. Ewing GW (2010) Mathematical modeling the neuroregulation of blood pressure using a cognitive top-down approach. N Am J Med Sci 2: 341-352.

88. Sudakov KV (1987) The basic principles of the general theory of functional systems. Medicine S: 26-49.

89. Henry BA (2007) Hypothalamic Control of Food Intake and Body Weight. In: eLS. John Wiley and Sons Ltd, Chichester.

90. Levine AS, Kotz CM, Gosnell BA (2003) Sugars: hedonic aspects neuroregulation, and energy balance. Am J Clin Nutr 78: 834S-842S.

91. Cummings DE, Weigle DS, Frayo RS, Breen PA, Ma MK, et al. (2002) Plasma ghrelin levels after diet-induced weight loss or gastric bypass surgery. N Eng J Med 346: 1623-1630

92. Horvath TL, Diano S, Sotonyi P, Heiman M, Tschöp M (2001) Minireview: 
Citation: Ewing GW (2015) The Framework of a Mathematical Model of the Autonomic Nervous System and Physiological Systems: Using the Neuroregulation of Blood Glucose as an Example. J Comput Sci Syst Biol 8: 059-073. doi:10.4172/jcsb.1000172

ghrelin and the regulation of energy balance--a hypothalamic perspective. Endocrinology 142: 4163-4169.

93. Sakurai T, Akira A, Makoto I, Ichiyo M, Richard MC, et al. (1998) Orexins and orexin receptors: a family of hypothalamic neuropeptides and $\mathrm{G}$ protein coupled receptors that regulate feeding behaviour. Cell 92: 573-585.

94. Reizes O, Benoit SC, Clegg DJ (2007) Treatment of the Obese Patient. Contemporary Endocrinology 12: 1-444.

95. King AJ (2005) Multisensory integration: strategies for synchronization. Curr Biol 15: R339-341.

96. Stein BE, Stanford TR, Rowland BA (2009) The neural basis of multisensory integration in the midbrain: its organization and maturation. Hear Res 258: 4-15.

97. Stein BE, Rowland BA (2011) Organization and plasticity in multisensory integration: early and late experience affects its governing principles. Prog Brain Res 191: 145-163.

98. Macaluso E, Driver J (2005) Multisensory spatial interactions: a window onto functional integration in the human brain. Trends Neurosci 28: 264-271.

99. Sivak M (1996) The information that drivers use: is it indeed $90 \%$ visual? Perception 25: 1081-1089.

100.Ewing GW, Parvez SH, Grakov IG (2011) Further Observations on Visual Perception: the influence of pathologies upon the absorption of light and emission of bioluminescence. The Open Systems Biology Journal 4: 1-7.

101. Tests and diagnosis. Diseases and Conditions Autonomic Neuropathy.

102. Valsalva Maneuver.

103.Parry SW, Kenny RA (1999) Tilt table testing in the diagnosis of unexplained syncope. QJM 92: 623-629.

104.Bielefeldt K (2012) Gastroparesis: concepts, controversies, and challenges. Scientifica (Cairo) 2012: 424802.

105. Riedel A, Braune S, Kerum G, Schulte-Mönting J, Lücking CH (1999) Quantitative sudomotor axon reflex test (QSART): a new approach for testing distal sites. Muscle Nerve 22: 1257-1264.

106. Illigens BM, Gibbons $\mathrm{CH}$ (2009) Sweat testing to evaluate autonomic function. Clin Auton Res 19: 79-87.

107. Klinghardt D (2003) The Neurophysiology of Light, The Five Pathways. Journa of Optometric Phototherapy 35-40.

108. Gottlieb RL, Wallace LB (2010) Syntonic phototherapy. Photomed Laser Surg 28: 449-452.

109. Barton J, Pretty J (2010) What is the best dose of nature and green exercise for improving mental health? A multi-study analysis. Environ Sci Technol 44: 3947-3955.

110. Hofer H, Carroll J, Neitz J, Neitz M, Williams DR (2005) Organization of the human trichromatic cone mosaic. J Neurosci 25: 9669-9679.

111. Vandewalle G, Collignon O, Hull JT, Daneault V, Albouy G, et al. (2013) Blue light stimulates cognitive brain activity in visually blind individuals. J Cogn Neurosci 25: 2072-2085.

112. Krakow SV (1941) Color vision and the autonomic nervous system. J Opt Soc Am 31: 335-342.

113. Dale H, Matheson M (2007) Colour Design Schemes for Long-term Healthcare Environments. Arts and Humanities Research Council.

114. Devlin AS, Arneill A (2003) Health care environments and patient outcomes. Environment and Behaviour 35: 665-694.

115. Birren F (1959) The effects of color on the human organism. Am J Occup Ther 13: $125-129$ passim.

116. Gernes US, Hornung PM (2003) The Medicine of Colours.

117. Van Someren EJ, Kessler A, Mirmiran M, Swaab DF (1997) Indirect bright ligh improves circadian rest-activity rhythm disturbances in demented patients. Biol Psychiatry 41: 955-963.

118. Pellegrini RJ, Schauss AG, Miller ME (1981) Room Color and Aggression in a Criminal Detention Holding Cell: A Test of the "Tranquilizing Pink" Hypothesis. Orthomolecular Psychiatry 10:174-181.

119. Corey LJ, Wallace MA, Harris SH, Casey B (1986) Psychiatric ward atmosphere. J Psychosoc Nurs Ment Health Serv 24: 10-16

120. Ulrich RS (1984) View through a window may influence recovery from surgery Science 224: 420-421.

121. Ismail GM, Whitaker D (1998) Early detection of changes in visual function in diabetes mellitus. Ophthalmic Physiol Opt 18: 3-12.

122. Kurtenbach A, Schiefer U, Neu A, Zrenner E (1999) Preretinopic changes in the colour vision of juvenile diabetics. Br J Ophthalmol 83: 43-46.

123. Daley ML, Watzke RC, Riddle MC (1987) Early loss of blue-sensitive color vision in patients with type I diabetes. Diabetes Care 10: 777-781.

124. Hardy KJ, Lipton J, Scase MO, Foster DH, Scarpello JH (1992) Detection of colour vision abnormalities in uncomplicated type 1 diabetic patients with angiographically normal retinas. $\mathrm{Br} \mathrm{J}$ Ophthalmol 76: 461-464.

125. Beisswenger PJ, Makita Z, Curphey TJ, Moore LL, Jean S, et al. (1995) Formation of immunochemical advanced glycosylation end products precedes and correlates with early manifestations of renal and retinal disease in diabetes. Diabetes 44: 824-829.

126. Stitt AW (2005) The maillard reaction in eye diseases. Ann N Y Acad Sci 1043 $582-597$

127.Ewing GW (2013) A Comparison of the Diagnostic Scope of Biomarker techniques, Genetic Screening and Virtual Scanning. Immunology, Endocrine and Metabolic Agents in Medicinal Chemistry 13: 35-45.

128. Martinek K, Berezin IV (1979) Artificial light-sensitive enzymatic systems as chemical amplifiers of weak light signals. Photochem Photobiol 29: 637-649.

129. Hug DH, O'Donnell PS, Hunter JK (1980) Light activation of enzymes. Photochem Photobiol 32: 841-848.

130. Azeemi ST, Raza SM, Yasinzai M (2008) Colors as catalysts in enzymatic reactions. J Acupunct Meridian Stud 1: 139-142.

131. Mizoguchi K, Yuzurihara M, Ishige A, Sasaki H, Chui DH, et al. (2000) Chronic stress induces impairment of spatial working memory because of prefrontal dopaminergic dysfunction. J Neurosci 20: 1568-1574.

132. Dias-Ferreira E, Sousa JC, Melo I, Morgado P, Mesquita AR, et al. (2009) Chronic stress causes frontostriatal reorganization and affects decisionmaking. Science 325: 621-625.

133. Tsigos C, Chrousos GP (2002) Hypothalamic-pituitary-adrenal axis, neuroendocrine factors and stress. J Psychosom Res 53: 865-871.

134. Metcalfe C, Davey Smith G, Macleod J, Heslop P, Hart C (2003) Self-reported stress and subsequent hospital admissions as a result of hypertension, varicose veins and haemorrhoids. J Public Health Med 25: 62-68.

135.Rutter M (2006) Invited Talk: Long-Term Effects of Early Institutional Deprivation: Findings From an Adoption Study and Implications for Causal Mechanisms. 18th Annual Convention of the Association of Psychological Science, NY, 2006.

136. Nabavi S, Fox R, Proulx CD2, Lin JY3, Tsien RY4, et al. (2014) Engineering a memory with LTD and LTP. Nature 511: 348-352.

137. Folcher M, Oesterle S, Zwicky K, Thekkottil T, Heymoz J, et al. (2014) Mind controlled transgene expression by a wireless-powered optogenetic designer cell implant. Nat Commun 5: 5392.

138. Roberts JE (1995) Visible light induced changes in the immune response through an eye-brain mechanism (photoneuroimmunology). J Photochem Photobiol B 29: 3-15.

139.Zagulova DV, Podkopaeva TI, Vasil'ev VN, Medvedev MA (2001) Effect of audiovisual stimulation on heart rhythm variability. Bull Exp Biol Med 131: 273275.

140. Furchgott RF, Ignarro LJ, Murad F (1998) Nitric oxide as a signalling molecule in the cardiovascular system. Wirz-Justice A (1998) Beginning to see the light. Arch Gen Psychiatry 55: 861-862.

141. Satlin A, Volicer L, Ross V, Herz L, Campbell S (1992) Bright light treatment of behavioral and sleep disturbances in patients with Alzheimer's disease. Am J Psychiatry 149: 1028-1032.

142. Oren DA, Wisner KL, Spinelli M, Epperson CN, Peindl KS, et al. (2002) An open trial of morning light therapy for treatment of antepartum depression. Am J Psychiatry 159: 666-669. 
Citation: Ewing GW (2015) The Framework of a Mathematical Model of the Autonomic Nervous System and Physiological Systems: Using the Neuroregulation of Blood Glucose as an Example. J Comput Sci Syst Biol 8: 059-073. doi:10.4172/jcsb.1000172

143. Kostoglou-Athanassiou I, Treacher DF, Wheeler MJ, Forsling ML (1998) Bright light exposure and pituitary hormone secretion. Clin Endocrinol (Oxf) 48: 73-79.

144. Holick MF (2004) Sunlight and vitamin D for bone health and prevention of autoimmune diseases, cancers, and cardiovascular disease. Am J Clin Nutr 80: 1678S-88S.

145. Randawon P (2001) Bioresonance Information Laser Therapy of Diabetes Mellitus. Laser Florence 4903: 146-153

146. Longo $L$ (2008) The role of laser in diabetes management. Proceedings of Light-Activated Tissue Regeneration and Therapy Conference. Lecture Notes in Electrical Engineering 12: 215-220.

147. Wileman SM, Eagles JM, Andrew JE, Howie FL, Cameron IM, et al. (2001) Light therapy for seasonal affective disorder in primary care: randomised controlled trial. Br J Psychiatry 178: 311-316.

148. Lam RW, Levitt AJ, Levitan RD, Enns MW, Morehouse R, et al. (2006) The Can-SAD study: a randomized controlled trial of the effectiveness of light therapy and fluoxetine in patients with winter seasonal affective disorder. Am J Psychiatry 163: 805-812.

149. Anderson DJ (1989) The treatment of migraine with variable frequency photostimulation. Headache 29: 154-155.

150. Mayke B, Koek G, Sigurdsson V, van Weelden H, Steegmans PHA, et al (2010) Cost effectiveness of home ultraviolet B phototherapy for psoriasis: economic evaluation of a randomised controlled trial (PLUTO study). British Medical Journal 340: c1490.

151. Vandewalle G, Archer SN, Wuillaume C, Balteau E, Degueldre C, et al. (2011) Effects of light on cognitive brain responses depend on circadian phase and sleep homeostasis. J Biol Rhythms 26: 249-259.

152. Houreld N, Abrahamse H (2008) He-Ne Laser Irradiation Stimulates Proliferation and Migration of Diabetic Wounded Fibroblast Cells. In Proceedings of Light-Activated Tissue Regeneration and Therapy Conference. Lecture Notes in Electrical Engineering 12: 221-232.

153. The Nobel Prize in Physiology or Medicine 1903. Nobelprize.org. Nobel Media AB 2014.

154.Cremer RJ, Perryman PW, Richards DH (1958) Influence of light on the hyperbilirubinaemia of infants. Lancet 1: 1094-1097.

155.Pigott HE, Cannon R (2014) Neurofeedback is the Best Available First-Line Treatment for ADHD: What is the Evidence for this Claim? NeuroRegulation 1: 4-23

156. Liddle E, Jackson G, Jackson S (2005) An evaluation of a visual biofeedback intervention in dyslexic adults. Dyslexia 11: 61-77.

157. Dewan EM, Menkin MF, Rock J (1978) Effect of photic stimulation on the human menstrual cycle. Photochem Photobiol 27: 581-585.

158. Hashmi JT, Huang YY, Sharma SK, Kurup DB, De Taboada L, et al. (2010) Effect of pulsing in low-level light therapy. Lasers Surg Med 42: 450-466.

159. Minatel DG, Frade MA, França SC, Enwemeka CS (2009) Phototherapy promotes healing of chronic diabetic leg ulcers that failed to respond to other therapies. Lasers Surg Med 41: 433-441.

160. Houreld NN (2014) Shedding light on a new treatment for diabetic wound healing: a review on phototherapy. Scientific World Journal 2014: 398412.

161.Fan BG, Andrén-Sandberg A (2007) Photodynamic therapy for pancreatic cancer. Pancreas 34: 385-389.

162. Ewing GW (2009) Does an improved understanding of the nature and structure of the Physiological Systems lead to a better understanding of the therapeutic scope of Complementary and Conventional Medicine? J Comp Sci Syst Biol 2: $174-179$.

163. Vysochin YV, Lukoyanov VV, Yaichnikov IK, Tkachuk MI, Chyev VA, et al. (2003) Methodology and Technology of Invigoration of Different Population Orders. In: Consolidated 5 year Research Plan of Physical Training, Sports and Tourism State Committee of the Russian Federation.

164.Cheng KJ (2014) Neurobiological mechanisms of acupuncture for some common illnesses: a clinician's perspective. J Acupunct Meridian Stud 7 : 105-114.

165. Benedetti $F$ (2013) Placebo and the new physiology of the doctor-patien relationship. Physiol Rev 93: 1207-1246.
166. Weissmark MS, Giacomo DA (1995) Measuring therapeutic interactions: research and clinical applications. Psychiatry 58: 173-188

167.Pullen R, Tabatha M (2010) Fostering therapeutic nurse-patient relationships Nursing Made Easy 8: 4

168. Ramjan LM (2004) Nurses and the 'therapeutic relationship': Caring for adolescents with anorexia nervosa. J Adv Nurs 45: 495-503.

169.(2000) Standard for the Therapeutic Nurse-Client Relationship. Nurses Association of New Brunswick.

170. Hewitt J, Coffey M (2005) Therapeutic working relationships with people with schizophrenia: literature review. J Adv Nurs 52: 561-570.

171.Dziopa F, Ahern K (2008) What Makes a Quality Therapeutic Relationship in Psychiatric/Mental Health Nursing: A Review of the Research Literature. The Internet Journal of Advanced Nursing Practice 10: 1.

172. Ulrich RS, Simons RF, Losito BD, Fiorito E, Miles MA, et al. (1991) Stress recovery during exposure to natural and urban environments. Journal of Environmental Psychology 11: 201-230.

173. Topf M (1999) Does the environment of the hospital affect recovery? J Health Serv Res Policy 4: 127.

174.Epp T, MacPhee R, Allman A (2001) Let there be light: The aging eye needs more illumination than is available in many facilities. Canadian Nursing Home 12: 4.

175. Beauchemin KM, Hays $P$ (1996) Sunny hospital rooms expedite recovery from severe and refractory depressions. J Affect Disord 40: 49-51.

176. Benedetti F, Colombo C, Barbini B, Campori E, Smeraldi E (2001) Morning sunlight reduces length of hospitalization in bipolar depression. J Affect Disord 62: 221-223.

177. Walch JM, Rabin BS, Day R, Williams JN, Choi K, et al. (2005) The effect of sunlight on postoperative analgesic medication use: a prospective study of patients undergoing spinal surgery. Psychosom Med 67: 156-163.

178. Lovell BB, Ancoli-Israel S, Gevirtz R (1995) Effect of bright light treatment on agitated behaviour in institutionalized elderly subjects. Psychiatry Res 57: 7-12.

179.Baker CF (1984) Sensory overload and noise in the ICU: sources of environmental stress. CCQ 6: 66-80

180. Wysocki $A B$ (1996) The effect of intermittent noise exposure on wound healing Adv Wound Care 9: 35-39.

181. Baker CF (1992) Discomfort to environmental noise: heart rate responses of SICU patients. Crit Care Nurs Q 15: 75-90.

182. Southwell MT, Wistow G (1995) Sleep in hospitals at night: are patients' needs being met? J Adv Nurs 21: 1101-1109.

183. Nova online. Cracking the code of life.

184. Shannahoff-Khalsa DS, Kennedy B, Yates FE, Ziegler MG (1996) Ultradian rhythms of autonomic, cardiovascular, and neuroendocrine systems are related in humans. Am J Physiol 270: R873-887.

185. Allsworth JE, Clarke J, Peipert JF, Hebert MR, Cooper A, et al. (2007) The influence of stress on the menstrual cycle among newly incarcerated women. Womens Health Issues 17: 202-209.

186. Hankey A, Ewing E (2007) New light on chromotherapy: Grakov's 'Virtual Scanning' system of medical assessment and treatment. Evid Based Complement Alternat Med 4: 139-144.

187. Ewing GW, Ewing EN (2007) Virtual Scanning - a new generation of medical technology - beyond biomedicine?

188. Ewing G, Ewing E, Hankey A (2007) Virtual scanning--a new system of medical assessment and treatment: Part I. Assessment. J Altern Complement Med 13: 271-285.

189. Montague Healthcare

190.Ewing GW (2014) Strannik Virtual Scanner. Strannik Operating Manual.

191. Nwose EU, Ewing GW, Ewing EN (2009) Migraine can be managed with Virtual Scanning: case report. The Open Complementary Medicine Journal 1:16-18.

192. Ewing GW, Parvez SH (2012) The Influence of Pathologies upon Sensory 
Citation: Ewing GW (2015) The Framework of a Mathematical Model of the Autonomic Nervous System and Physiological Systems: Using the Neuroregulation of Blood Glucose as an Example. J Comput Sci Syst Biol 8: 059-073. doi:10.4172/jcsb.1000172

Perception and Sensory Coordination in Children with Developmental Dyslexia and Learning Disorders: A Unified Theory of Developmental Dyslexia. N Am J Med Sci 4: 109-116.

193. Liddle E, Jackson G, Jackson S (2005) An evaluation of a visual biofeedback intervention in dyslexic adults. Dyslexia 11: 61-77.

194. Huang TL, Charyton C (2008) A comprehensive review of the psychological effects of brainwave entrainment. Altern Ther Health Med 14: 38-50.

195. Ewing GW, Nwose EU, Ewing EN (2009) Obstructive sleep apnea management with interactive computer technology and nutrition: two case reports. J Altern Complement Med 15: 1379-1381.

196. Ewing GW (2013) The successful treatment of Dysarthria using Biofeedback: a case study. Biogenic Amines.

197.Ewing GW, Ewing EN (2007) Virtual Scanning. The Next Generation of Healthcare: Beyond Biomedicine? Montague Healthcare books.

198. Kiecolt-Glaser JK, Glaser R (2002) Depression and immune function: central pathways to morbidity and mortality. J Psychosom Res 53: 873-876.

199. Ewing G, Ewing E, Hankey A (2007) Virtual scanning--a new system of medical assessment and treatment: Part I. Assessment. J Altern Complement Med 13: 271-285

200. Bhattacharjee $Y$ (2007) Psychiatric research. Is internal timing key to mental health? Science 317: 1488-1490
201. Abarbanel HD, Rabonovich MI, Selverston A, Bazhenov MV, et al. (1996) Synchronisation in Neural Networks Phys Usp 39: 337.

202. Womelsdorf T, Schoffelen JM, Oostenveld R, Singer W, Desimone R, et al. (2007) Modulation of neuronal interactions through neuronal synchronization. Science 316: 1609-1612.

203. Bower B (1998) All Fired Up: Perception May Dance to the Beat of Collective Neuronal Rhythms. Science News 153: 120-121.

204. Benedict C, Hallschmid M, Hatke A, Schultes B, Fehm HL, et al. (2004) Intranasal insulin improves memory in humans. Psychoneuroendocrinology 29: $1326-1334$

205.Booth A, Amato P (1991) Divorce and psychological stress. J Health Soc Behav 32: 396-407.

206. Simmen-Janevska K, Brandstätter V, Maercker A (2012) The overlooked relationship between motivational abilities and posttraumatic stress: a review. Eur J Psychotraumatol 3.

207. Friedman EH (2007) A Failure of Nerve: Leadership in the Age of the Quick Fix.

208. Bodnar JC, Kiecolt-Glaser JK (1994) Caregiver depression after bereavement: chronic stress isn't over when it's over. Psychol Aging 9: 372-380.

209. Jaremka LM, Fagundes CP, Peng J, Bennett JM, Glaser R, et al. (2013) Loneliness promotes inflammation during acute stress. Psychol Sci 24: 1089-1097. 